\title{
The Attitudes of Primary School Teachers towards Leisure*
}

\author{
Özden Tepeköylü Öztürk ${ }^{1}$, Mümine Soytürk ${ }^{2}$, Yeliz Ilgar Doğan ${ }^{1}$ \\ ${ }^{1}$ Faculty of Sport Sciences, Pamukkale University, Denizli, Turkey \\ ${ }^{2}$ Faculty of Sport Sciences, Celal Bayar University, Manisa, Turkey \\ Correspondence: Özden Tepeköylü Öztürk, Faculty of Sport Sciences, Pamukkale University, Denizli, Kınıklı Campus, \\ 20020, Turkey.
}

Received: February 18, 2019

Accepted: March 11, 2019

Online Published: March 13, 2019

doi:10.11114/jets.v7i4.4142

URL: https://doi.org/10.11114/jets.v7i4.4142

\begin{abstract}
This study aims to analyze the attitudes of primary school teachers towards leisure. It also aims to determine whether the attitudes of primary school teachers vary according to their gender and leisure activities they attend. A total of 355 primary school teachers ( $X_{\text {age }}=45.08 \pm 7.91$ ), including 188 females and 167 males, volunteered to participate in this study. "Leisure Attitude Scale" developed by Beard and Ragheb (1982) and adapted into Turkish by Akgül and Gürbüz (2010) and "General Information Form" were utilized to collect data. The findings of this study indicates that the leisure attitudes levels of teachers were quite high $\left(X_{\text {mean }}=4.28 \pm .33\right)$. Also according to gender of the participants, a significant difference was found in favor of the female teachers in regards to the attitude of leisure in the cognitive sub-dimension and in total points but not in the affective and behavioral sub-dimensions. In terms of the most preferred leisure activity, there was a significant difference in the behavioral sub-dimension of the leisure attitude scale of teachers, whereas there was no statistically significant difference in the cognitive, affective sub-dimensions and total scores. Accordingly, teachers who preferred physical activities in leisure had higher points than the ones who preferred other activities with regards to the behavioral sub-dimensional. In addition, no significant relationship was found between the ages of the teachers, the years of professional service, the leisure attitude scale sub-dimensions and total score.
\end{abstract}

Keywords: leisure attitude, primary school, teachers, students

\section{Introduction}

Today, education is one of the most important factors in the structuring and raising of an individual. And the most important element in education is teacher. They start the process of teacher-student relationship by interacting with the child by means of emotion, thought and behaviors. In this process, while teachers provide academic learning by transferring their knowledge, they also provide different behavioral changes in students with their personality, behaviors and positive/negative attitudes (Kılıç et al., 2004). In other words, education environment is related with the attitudes of teachers (Ergün, 1998). While students are affected by the behaviors of teachers, they are also affected by the attitudes of teachers (Kyriakides et al., 2009; Zang et al., 2018).

According to Smith (1968), attitude is "an inclination that creates the thought, emotion and behaviors of an individual which is attributed to him/her about a psychological object in an orderly manner" (Kağıtçıbaşı, 2006:102). It is an inclination of reacting positive or negative towards this object. Attitude cannot be observed directly, it should be measured with observable actions and it is a hypothetical concept (Ajzen, 2011:3). It has three elements as emotion, thought and behavior. When these three elements exist at the same time influentially, it can be stated that there is a powerful attitude (Kağıtçıbaşı, 2006:103). The psychological object here can be a person, an object, an institution, an incident, anything and a concept such as leisure. In this context, the attitude towards leisure are positive and negative reactions that constitute of emotion, thought, behavior, experience and knowledge about the leisure and activities that can be performed in leisure (Teaff, 1975). The attitude towards leisure includes perception, knowledge, belief, emotion, thought and behavior about leisure. For this reason, in order to completely understand the attitude towards leisure, it

*This study was presented on XIX. European Conference on Social and Behavioral Sciences January 30-31, 2019 Rome, Italy. 
should be discussed along with cognitive, affective and behavioral components (Teixeria \& Freire, 2013). According to Ragheb and Beard (1982), cognitive component includes general knowledge and beliefs about how the general features of leisure are related to life quality of individuals. Affective component is the level of liking the experiences and activities of leisure of individuals. Behavioral component is about activities that were performed in the past, being performed at the moment, and would be performed in the future regarding leisure activities. The attitude towards leisure is related to many factors regarding leisure behavior with its multi-dimensional structure. From the studies in the literature it can be observed that it is related to perception of freedom in leisure (Siegenthaler \& O'Dell, 2000), leisure satisfaction (Kim et al., 2015; Freire \& Teixeria; 2018), motivation (Chen, 2002) and participation to leisure (Sivan, Fung, Fung \& Ruskin, 2013).

Attitudes are directly related to actions and may show a number of changes during the course of our lives (Yanık, 2018). If a person has positive emotion and thinks positive towards an object, there is a possibility of performing a consistent action towards that (Pehlivan, 2010). In this context, the possibility of utilizing leisure more efficient and productive can be expected to be higher in teachers who maintain a positive attitude towards leisure. Participation in leisure on optimal level, utilizing it efficiently and getting efficiency from it directly or indirectly affects factors such as satisfaction (Chick et al., 2016; Choi \& Yoo, 2017), psychological well-being (Sivan, Fung, Fung \& Ruskin, 2013; Kim et al, 2015) and happiness (Nawjin \& Veenhoven, 2013) regarding life and satisfaction, productivity (Choi \& Yoo, 2017) and exhaustion regarding work life (Hoeksma et al., 1994). It is considered that a teacher who is satisfied with his/her occupation and is not exhausted would be more beneficial and inspirational to his/her students. It is more important for primary school teachers who would guide students in primary school where many features about personality and various skills are acquired to have positive emotions towards their occupation. Because experiences in the process of the relationship between teacher-student in this period affects the whole life of students (Kildan, 2011). In his research, Cassidy (2005) has observed that the teachers' encouraging behaviors towards leisure to children affect the attitude towards leisure in adulthood. Further, teachers can be regarded as role models in social sense. In this sense, the emotion, thought, behavior and ultimately attitudes of teachers out of their school life gain importance. For this reason, in this study, it was attempted to determine the attitudes of primary school teachers towards leisure. Furthermore, the differences in the attitudes of teachers towards leisure were examined in accordance with their gender and leisure activities they participate in and the relationships of leisure according to the age and the service year in the occupation variables of the teachers were examined.

\section{Method}

\subsection{Research Design and Sample}

Quantitative research techniques were used in this research. It is a descriptive research. The population of the study consists of 1872 primary school teachers, working in 97 schools located in the central districts of Denizli province. In the sample there are $355\left(X_{\text {age }}=46.08, \pm 7.91\right)$ primary school teachers, 188 female $\left(X_{\text {age }}=44.59 \pm 8,14\right) 167$ male $\left(X_{\text {age }}\right.$ 45.64 \pm 7.62$)$, who were determined with simple random sampling technique. The sample size was determined by utilizing the table "acceptable sample sizes for certain populations" that was created by Sekaran (1992) (Altunışık et al., 2007).

\subsection{Data Collection Tools}

In the study, "The Leisure Attitude Scale" that was developed by Beard and Ragheb (1982) and translated to Turkish by Akgül and Gürbüz (2011) and "Personal Information Form" that was developed by the researchers were used as data collection tools.

\subsubsection{The Leisure Attitude Scale (LAS)}

The scale consists of 36 items. It has 3 sub-dimensions as affective, cognitive and behavioral. The answers in the scale which is 5 point likert type range from "Strongly Agree (5)" to "Strongly Disagree (1)". It was determined that the factor loads of items in the Turkish form range from 412 to 814 . As a result of the analyses, it was understood that the internal consistency coefficients of the scale range from .81 to .92 . The total reliability coefficient of the scale was determined as 0.97 . The cronbach alpha is .94 as the reliability analysis that was conducted within the context of this study.

\subsubsection{Personal Information Form (PIF)}

Information about the independent variables of the research were determined with "Personal Information Form" which was developed by the researchers.

\subsection{Collection of the Data}

Official permissions were acquired from the necessary institutions in order to collect data. Then, with these permissions, measuring instruments were handed to and collected from the teachers by giving necessary explanations. 


\subsection{Statistical Analysis of the Data}

The data were evaluated by using frequency, arithmetic mean, standard deviation, t-test, Pearson correlation analysis and statistical test techniques. T- test was used for the differences in sub-dimension and total scores of LAS according to the teachers' gender and leisure type they participate in and Pearson correlation analysis was conducted for the relationships about the age and occupation duration. Whether or not the data provide the prerequisites of parametric tests were decided by examining the skewness and kurtosis values (normal distribution status of the data). In order to determine the reliability of the scale within the context of the research that was used in the study, cronbach alpha internal consistency coefficients were calculated. Type 1 error was accepted as $5 \%$.

\section{Findings}

Table 1. Descriptive statistic results regarding the attitudes of teachers towards leisure

\begin{tabular}{lccccc}
\hline & $\mathrm{n}$ & Min. & Max. & X & Std. Error \\
\hline Affective & 355 & 3.42 & 5.00 & 4.34 & .36 \\
Cognitive & 355 & 2.42 & 5.00 & 4.32 & .36 \\
Behavioral & 355 & 3.08 & 5.00 & 4.19 & .44 \\
\hline LAS Total & 355 & 3.28 & 5.00 & 4.28 & .33 \\
\hline
\end{tabular}

When the Table 1 is examined, it can be observed that the attitude scores of primary school teachers towards leisure is quite high, as above average When the sub-dimension scores were observed it was determined that the highest score was in affective sub-dimension and the lowest score was in behavioral sub-dimension. When generally evaluated, it can be stated that there are positive attitudes towards leisure.

Table 2. T-test result that shows the attitudes of teachers towards leisure according to gender variable

\begin{tabular}{|c|c|c|c|c|c|c|c|}
\hline LAS & Gender & $\mathrm{N}$ & $X$ & sd & $\mathrm{df}$ & $\mathrm{t}$ & $\mathrm{p}$ \\
\hline \multirow{2}{*}{ Affective } & Female & 188 & 4.32 & .03 & 353 & .734 & .463 \\
\hline & Male & 167 & 4.35 & & & & \\
\hline \multirow{2}{*}{ Cognitive } & Female & 188 & 4.28 & .03 & 353 & 2.146 & .033 \\
\hline & Male & 167 & 4.37 & & & & \\
\hline \multirow{2}{*}{ Behavioral } & Female & 188 & 4.20 & .04 & 353 & .287 & .774 \\
\hline & Male & 167 & 4.19 & & & & \\
\hline \multirow{2}{*}{ LAS Total } & Female & 188 & 4.27 & .03 & 353 & .939 & .348 \\
\hline & Male & 167 & 4.30 & & & & \\
\hline
\end{tabular}

According to Table 2, while there is a significant difference in terms of gender factor in cognitive sub-dimension of the attitude of primary school teachers towards leisure scale, it was observed that there wasn't a statistically significant difference in behavioral sub-dimensions and total score. According to this, it was determined that in the cognitive sub-dimension of the attitude of primary school teachers towards leisure, the scores of males are higher than the scores of female teachers.

Table 3. T-test results that shows the attitude of teachers towards leisure according to the most preferred type of leisure activity

\begin{tabular}{|c|c|c|c|c|c|c|c|}
\hline LAS & $\begin{array}{l}\text { PA* } \\
\text { Type }\end{array}$ & $\mathrm{N}$ & $\mathrm{X}$ & $\mathrm{sd}$ & $\mathrm{df}$ & $\mathrm{t}$ & $\mathrm{p}$ \\
\hline \multirow{2}{*}{ Affective } & Other** & 203 & 4.34 & .04 & 283.16 & .000 & 1.00 \\
\hline & PA* & 152 & 4.34 & & & & \\
\hline \multirow[b]{2}{*}{ Cognitive } & Other** & 203 & 4.32 & .04 & 291.03 & .255 & .79 \\
\hline & PA* & 152 & 4.33 & & & & \\
\hline \multirow{2}{*}{ Behavioral } & Other** & 203 & 4.15 & .04 & 304.07 & 2.017 & .04 \\
\hline & PA* & 152 & 4.25 & & & & \\
\hline \multirow{2}{*}{ LAS Total } & Other** & 203 & 4.27 & .03 & 282.40 & .988 & .32 \\
\hline & PA* & 152 & 4.30 & & & & \\
\hline
\end{tabular}

* Physical Activity

** Activities of artistic, intellectual, social, practical works etc.

According to Table 3, while there is a significant difference in terms of the most preferred type of leisure activity in behavioral sub-dimension of the attitude of primary school teachers towards leisure scale, it was observed that there wasn't a statistically significant relationship in cognitive and affective sub-dimensions and total score. According to this, it was determined that in the behavioral sub-dimension of the attitude of primary school teachers towards leisure scale, the scores of teachers who prefer physical activity were higher than those who prefer other activities. Further, it was observed that most preferred type of activity is physical activity. 
Table 4. Pearson correlation analysis intended to determine the relationship between the attitude of teachers towards leisure and their age and their service duration in the occupation

\begin{tabular}{lcccc}
\hline $\mathrm{n}=355$ & Affective & Cognitive & Behavioral & LAS Total \\
\hline Age & .031 & .042 & .042 & .046 \\
Service Duration & -.009 & -.032 & .006 & -.013 \\
\hline
\end{tabular}

In Table 4, when the LAS total score and sub-dimension correlations between the ages of the teachers and their service duration in the occupation were examined, it was observed that there weren't significant relationships between the variables. According to this, it can be stated that the attitudes of teachers towards leisure don't change in accordance with their age and service duration.

\section{Discussion}

According to the findings of the research, it was observed that the total and sub-dimension scores of attitude of primary school teachers towards leisure are quite high. Under these circumstances, it can be stated that teachers have positive attitudes towards leisure. When evaluated in terms of sub-dimensions, it is considered that cognitively, they have information, positive opinions and believe the benefits of the activities regarding leisure. Because cognitive dimension includes belief and information about the relationship between leisure and life quality (Ragheb \& Beard, 1982). It was observed that they were affectively interested in and liked these activities and participated in behaviorally, however, when the mean scores are examined, they perform the activities in this sub-dimension less, compared to other dimensions. In the study of Ustun et al. (2017), it can be seen that teachers are interested in leisure activities, but they don't participate in as much as they are interested.

According to the genders of the teachers that participated in the research, there wasn't a significant difference in affective and behavioral dimensions and total leisure attitude. However, it was observed that the knowledge and thoughts of males towards leisure in cognitive dimension were more positive than females. This finding could result from the fact that female and male teachers could not have reached leisure sources equally. According to Muzindutsi and Masango (2015), the possibilities of reaching leisure sources create difference in parameters about leisure. For this reason, different findings are acquired on the basis of gender towards the attitude of leisure in different cultures (Akgül, 2011). According to Henderson et al. (1996), men and women encounter different incidents in social environment in the society. Therefore, the activities women and men, who undertake different social roles, prefer in their leisure can be different. For this reason, it is considered that the gender factor can affect their opinions or their attitude towards leisure. Furthermore, in terms of social roles, the work and domestic life responsibilities of women and especially working mothers bring along the conflict of work-leisure and it may cause them to consider leisure more negative than men.

It can be observed that in the behavioral sub-dimension of the attitudes of primary school teachers towards leisure who participate in physical activity according to the most participated type of activity are higher than those who participate in other activities (activities of artistic, intellectual, social, practical works etc.) Further, according to the findings of the study, it was determined that the most preferred type of activity is physical activities. In a research, it was determined that the most preferred activity is physical activities (Binbaşığlu and Tuna, 2014). Karaman et al. (2016) stated that the attitudes of individuals towards leisure who participate in dancing activities which is a physical activity are quite positive.

It was determined that there wasn't a significant relationship between the attitudes of primary school teachers towards leisure and their age and their service duration. According to this, it can be stated that the attitudes of teachers towards leisure does not change as their age and service duration progress. There wasn't a research in the literature that discusses this finding. However, this situation is related to the professional liability, work load and sharing similarities of daily and weekly leisure of teachers regardless of their biological age and service duration.

\section{Result and Recommendations}

It was observed that the knowledge, belief, perception, emotion and thoughts of primary school teachers towards leisure are quite positive, they like leisure activities, but they do not participate in these activities as much as they like. For this reason, enhancing studies on the behavioral dimension would provide more detailed information for the explanation of the reasons about the participation. Furthermore, class teachers attend to lessons whole day and whole week, different than branch teachers. In this context, providing institutional leisure opportunities would affect emotion, thought, behaviors and ultimately leisure attitudes positively. Because, participation in leisure positively affects parameters about leisure.

\section{References}

Ajzen, I. (2011). Attitudes personality and behaviour (2nd ed.). New York, USA, Open University Press.

Akgül, B. M. (2011). Evaluation of attitudes towards leisure activities in different cultures: An example of London and 
Ankara. (Doctorial thesis, Gazi University, Institute of Health Sciences, Department of Physical Education and Sports, Ankara, Turkey).

Akgül, B. M., \& Gürbüz, B. (2011). Leisure attitude scale: the study of reliability and validity. Gazi Journal of Physical Education and Sport Sciences, 7(1), 37-43.

Altunışık, R., Coşkun, R., Bayraktaroğlu, S., \& Yıldırım, E. (2007). Sosyal bilimlerde araştırma yöntemleri-spss uygulamalı (5. Baskı) Sakarya, TR, Sakarya Yayıncılık.

Binbaşıoğlu, H., \& Tuna, H. (2014). College students' attitudes towards leisure: A study of vocational school students in eastern Anatolia region. Journal of Academic Approaches, 5(2), 74-93.

Cassidy, T. (2005). Leisure, coping and health: the role of social, family, school and peer relationship factors. British Journal of Guidance \& Counselling, 33(1), 51-66. https://doi.org/10.1080/03069880412331335830

Chen, H. (2002). The relationship between leisure attitude and leisure motivation in junior high school students. (Master thesis, Springfield College, School of Gradueta Studies. University of Oregon). Retrieved March 25, 2009, from http://millrace. uoregon.edu/kinpubs/elecprod/PSY2290Chen(16-2).pdf.

Chick, G., Hsu, Y. C., Yeh, C. H., Hsieh, C. M., Bae, S. Y., \& Larmolenko, S. (2016). Cultural consonance in leisure, leisure satisfaction, life satisfaction, and self-rated health in urban Taiwan. Leisure Sciences, 38(5), 402-423. https://doi.org/10.1080/01490400.2016.1141734

Choi, S. H., \& Yoo, Y. J. (2017). Leisure attitude and satisfaction with leisure and life: proposing leisure prioritization and justification. World Leisure Journal, 59(2), 140-155. https://doi.org/10.1080/16078055.2016.1216886

Ergün, M., \& Duman, T. (1998). Teacher behavior in critical situations. Journal of National Education, 137, 45-58.

Freire, T., \& Teixeria, A. (2018). The influence of leisure attitudes and leisure satisfaction on adolescents' positive functioning: The role of emotion regulation. Frontiers in Psychology, 9, 1349. https://doi.org/10.3389/fpsyg.2018.01349

Henderson K. A., Bialeschki, M. D., Shaw, S. M., \& Freysinger, V. J. (1996). Both gains and gaps: Feminist perspectives on women's leisure state college. USA, PA: Venture Publishing, Inc.

Hoeksma, J. H., Guy, J. D., Brown, C. K., \& Brady, J. L. (1994). The relationship between psychotherapist burnout and satisfaction with leisure activities. Psychotherapy in Private Practice, 12(4), 51-57.

Kağıtçıbaşı, Ç. (2006). Yeni İnsan ve İnsanlar (10. basım). İstanbul, TR, Evrim Yayın Evi.

Karaman, M., Ayyıldız, T., Okan, İ., \& Yaman, M. (2016). Investıgation of the relationship of happiness, leisure attitudes and life satisfaction levels of individuals who join recreative dancing activities. International Refereed Academic Journal of Sports, Health and Medical Sciences, 21, 75-93. https://doi.org/10.17363/SSTB.20162124009

Kildan, A. O. (2011). An examination of teacher-child relation according to various variables. Buca Faculty of Education Journal, 30, 103-120.

Kılıç, M., Kaya, A., Yıldırım, N., \& Genç, G. (2004). Eğitimci gözüyle öğretmen ve öğrenci. XIII. Ulusal Eğitim Bilimleri Kurultayı, 6-9 Temmuz, İnönü Üniversitesi, Eğitim Fakültesi, Malatya.

Kim, S., Sung, J., Park, J., \& Dittmore, S. W. (2015). The relationship among leisure attitude, satisfaction, and psychological wellbeing for college students. Journal of Physical Education and Sport, 15(1), 70-76.

Kyriakides, L., Creemers, B. P. M., \& Antoniou, P. (2009). Teacher behaviour and student outcomes: Suggestions for research on teacher training and professional development. Teaching and Teacher Education, 25(1), 12-23. https://doi.org/10.1016/j.tate.2008.06.001

Muzindutsi, P. F., \& Masango, Z. (2015). Determinants of leisure satisfaction among undergraduate students at a South African university. International Journal of Business and Management Studies, 7(2), 1-15.

Nawijn, J., \& Veenhoven, R. (2013). Happiness through leisure. In T. Freire (Ed.), Positive leisure science (pp. 193209). Dordrecht: Springer. https://doi.org/10.1007/978-94-007-5058-6_11

Pehlivan, Z. (2010). Analysis of physical self-perceptions of physical education teacher candidates and their attitudes toward teaching profession. Education and Science, 35(156), 126-141.

Ragheb, M. G., \& Beard, J. G. (1982). Measuring leisure attitude. Journal of Leisure Research, 14(2), 155-167. https://doi.org/10.1080/00222216.1982.11969512

Siegenthaler, K. L., \& O'dell, I. (2000). Leisure attitude, leisure satisfaction, and perceived freedom in leisure with 
family dyads. Leisure Sciences, 22, 281-296. https://doi.org/10.1080/01490409950202302

Sivan, A., Fung, A., Fung, L., \& Ruskin, H. (2013). Determinants of participation disposition in leisure among Hong Kong school students. Society and Leisure, 25(1), 155-170. https://doi.org/10.1080/07053436.2002.10707582

Teaff, J. E. (1975). An elderly leisure attitude schedule. 28th Annual Meeting of the Gerontological Society. Oct 26-30. Louıvillie, Kentucky.

Teixeira, A., \& Freire, T. (2013). The leisure attitude scale: Psychometrics properties of a short version for adolescents and young adults. Leisure/Loisir, 37(1), 57-67. https://doi.org/10.1080/14927713. 2013.776748

Ustun, D. U., Ersoy, A., \& Bisgin, H. (2017). An investigation on perceived constraints of teachers in relation to leisure activities. Turkish Journal of Sport and Exercise. 19(2), 157-161. https://doi.org/10.15314/tsed.301569

Yanik, M. (2018). Attitudes of university students towards sport. Journal of Education and Training Studies, 6(5), 111-117. https://doi.org/10.11114/jets.v6i5.3047

Zhang, Y., Jiang, G., Sun, Y., Zhao, X., \& Yu, X. (2018). Cross-cultural adaptation and psychometric properties of the Chinese version of the communication skills attitude scale among medical students in liaoning province, china: A cross-sectional study. BMJ open, 8(9), 8: E020931. https://doi.org/10.1136/bmjopen-2017-020931

\section{Copyrights}

Copyright for this article is retained by the author(s), with first publication rights granted to the journal.

This is an open-access article distributed under the terms and conditions of the Creative Commons Attribution license which permits unrestricted use, distribution, and reproduction in any medium, provided the original work is properly cited. 